\title{
The direct cost of disability of community-dwelling older persons in Belgium
}

\section{Authors}

Sophie Cès, Anne-Sophie Lambert, Johanna de Almeida Mello, Anja Declercq, Niko Speybroeck, Lieven Annemans, Jean Macq

- Sophie Cès, sophie.ces@uclouvain.be, 003276434 38, Université Catholique de Louvain, Institut de Recherche Santé et Société, clos chapelle aux champs, 301200 Bruxelles, Belgique

- Anne-Sophie Lambert, anne-sophie.lambert@uclouvain.be, Université Catholique de Louvain, Institut de Recherche Santé et Société, clos chapelle aux champs, 301200 Bruxelles, Belgique

- Johanna de Almeida Mello, johanna.mello@ kuleuven.be, Katholieke Universiteit Leuven, Centrum voor Zorgonderzoek en Consultancy, Minderbroedersstraat 8 postbus 5310 B-3000 Leuven

- Anja Declercq, anja.declercq@ kuleuven.be, Katholieke Universiteit Leuven, Centrum voor Zorgonderzoek en Consultancy, Minderbroedersstraat 8 postbus 5310 B-3000 Leuven

- Niko Speybroeck, niko.speybroeck@uclouvain.be, Université Catholique de Louvain, Institut de Recherche Santé et Société, clos chapelle aux champs, 301200 Bruxelles, Belgique

- Lieven Annemans, lieven.Annemans@ Ugent.be, Universiteit Gent, Universitair Centrum voor Verpleegkunde en Vroedkunde, UZ Gent, 5K3 (ingang 42), Corneel Heymanslaan 10, B - 9000 Gent, Belgique

- Jean Macq, jean.macq@uclouvain.be, Université Catholique de Louvain, Institut de Recherche Santé et Société, clos chapelle aux champs, 301200 Bruxelles, Belgique 


\section{Abstract}

Current policies aim to promote and develop community-based support of disabled elderly persons, yet knowledge of cost implications is insufficient. Thus, we aimed to estimate, for three disability profiles and three presence levels of the main informal carer (none, non-cohabitant, cohabitant), the cost of formal and informal support currently provided at home in Belgium.

In this cross-sectional study, a sample of 5,642 disabled elderly persons living at home was established between 2010 and 2015. The administrative database of the Belgian public health care insurance was merged with other prospective data on social care service utilization, informal care and disability.

The total cost of formal support ranged from $€ 725 €$ to $€ 1,344$ (on average, per person-month), depending on the three disability profiles identified. 25 per cent of persons with the highest level of disability (important functional limitations and cognitive impairment) and helped by a cohabitant carer, had a low total cost of formal support: below $€ 382$ on average, per month. Informal care represented the main cost component of total support costs in the three disability profiles (between $66 \%$ and $80 \%$ ). To prevent the worsening of situations of disabled older persons and their informal carers, a better detection of seriously disabled persons with low levels of formal support is crucial.

\section{Keywords}

Disabled persons, Aged, Caregivers, Costs and Cost Analysis, Long-term care

\section{Introduction}

Concerns over the economic implications of the ageing population are growing. Nowadays in Belgium, 16 per cent of older persons ( $\geq 65$ years old) report having significant mobility difficulties, while around 29 per cent report experiencing difficulties in performing at least one daily activity (Van der Heyden J and Charafeddine, 2014). In 2013, 8.4 per cent of elderly persons received residential 
care in Belgium (Vrijens et al., 2016) while in the four neighbouring countries, the rate varied between 4.1 and 5.6 per cent (OECD, 2016). Overall in Belgium, 4.9 per cent of older persons received longterm nursing home care in 2013 (Vrijens et al., 2016). With increases in longevity, the absolute number of disabled older persons is expected to rise, leading to increases in long-term care expenditures (Spillman and Lubitz, 2000). In order to keep these expenditures under control, it is believed that promotion and development of community-based support is a sustainable solution compared to institutional care. Estimating the cost of support currently provided to disabled older persons is therefore a crucial initial step to evaluate potential economic consequences of community support systems. To our knowledge, there has been no large-scale study published on the cost of support of community-dwelling disabled older persons in Belgium. Moreover, most of the international studies were limited to the estimation of additional costs borne by disabled persons in comparison with nondisabled persons (Antón, Braña and de Bustillo, 2016; Hirsch and Hill, 2016; Morciano, Hancock and Pudney, 2015; Wilkinson-Meyers et al., 2010) or on specific diseases, such as dementia (Gerves, Chauvin and Bellanger, 2014; Gustavsson, Cattelin and Jonsson, 2011; Gustavsson et al., 2010; Jonsson et al., 2006; Jönsson and Wimo, 2009; Quentin et al., 2010; Schwarzkopf et al., 2011; Suh, Knapp and Kang, 2006; Taylor Jr et al., 2001; Wimo et al., 2011).

In Belgium, the role of the state is to provide universal access to long-term care services by predominantly financing various 'benefits in-kind'. Long-term health care services for persons living at home (e.g. nursing, medical home care, and paramedical) are financed at the national level through the federal compulsory health insurance system (the National Institute of Health and Disability Insurance) covering 99 per cent of the population (OECD). Its funding is mainly based on social security contributions (from workers, employers and retirees) and also general taxes (Willemé et al., 2011). The driving principles for access to health care services are equal access and freedom of choice. The payment system is mainly based on fee-for-services. 
Support for at -home living services, mostly financed by taxes, are regulated at regional levels and organised locally to help persons in need with their Instrumental Activities of Daily Living (IADL) (e.g. domestic tasks) and with personal care. The aim is to prioritize the support of persons with the highest levels of need and those with low income. A co-payment is requested according to household financial resources. Alongside this system, since 2001 and regardless of functional limitations and income, a system of vouchers is also possible (financed by taxes). It was implemented to significantly reduce the labour costs of workers providing home care services (e.g. housework, meal preparation) or those outside the residence (e.g. shopping, transportation for persons with mobility limitations, or other specific chores, such as laundry or ironing). Funding for at-home living services using the voucher system is mainly provided by organisations from the private sector.

Intermediary care setting also exists between these home and residential care facilities: day care centres facilitate the daily support of persons living at home. They provide nursing care and rehabilitation, financed by the region, alongside user-financed occupational activities and catering. In nursing homes, care provisions are publicly financed based on a case-mix system determined by the disability profiles of residents and the number of health care staff (Van den Bosch et al., 2011). Boarding and lodging costs are financed mainly by residents (or in the case of financial incapacity, by relatives or the public municipal welfare). Finally, in Belgium, seven 'sickness funds', representing the political and religious spectrums, also play a significant role in the financing of long-term care services. The sickness funds offer complementary insurance to their members for specific health care provisions and home care services. Private insurance may also intervene in the funding of long-term care. To summarize, the support of disabled older persons in Belgium is mainly based on benefits inkind with a "multilevel governance" (Degavre et al., 2012) involving various organisations from the health care and social sectors. Such fragmentation of the long-term care system hinders the centralised management of resources at the micro-level which would allow for routine calculations of long-term care costs. Hence, to fill the knowledge gap in Belgium, we propose estimations based on resource costs that support disabled elderly persons at home. 
The aim of the study was to estimate the direct costs (medical and non-medical) (Annemans, 2008) to support disabled elderly persons at their home. Using a combined perspective, the following stakeholders were considered: public payers (the National Institute for Health and Disability (NIHDI) and the regional federated entities), disabled elderly persons and their main informal carers (identified as the person helping the older persons most of the time). For formal support, only the cost borne by the NIHDI was distinguished, as no data was available on the shared costs of other funding stakeholders.

The first objective was to estimate costs of the different funding stakeholders (NIHDI, informal carers and other stakeholders) and to identify the main cost components of the following three disability profiles: 1) functional limitations on IADL with low cognitive impairment: IADL ( $\operatorname{cogn}$.$) ; 2)$ Functional limitations on IADL and basic Activities of Daily Living (ADL): Func.; and 3) Functional limitations on IADL and ADL with significant cognitive impairment: Func. Cogn.. The second objective was to discuss the potential underuse of formal support by performing a cost benchmarking analysis of various situations at home, defined by the combination of three disability profiles and three presence levels of the main informal carer (none, non-cohabitant, cohabitant). We supposed that these two factors are the main determinants of support at home.

\section{Materials and methods}

\section{Study design and setting}

- This study was part of a broader research program (de Almeida Mello et al., 2016; De Almeida Mello et al., 2012) aiming to evaluate large-scale innovative bottom-up healthcare projects that support disabled elderly persons at home. Data were collected from 2010 until November 2016. The recruitment criteria was being 60 years of age or older and fulfilling 
one of the following scoring criteria: a score on the Edmonton Frail scale of at least six (total score from 6-7 = "vulnerable," to 12-17 = "severe frailty") (Rolfson et al., 2006);

- or at least a Score A- need for assistance to perform personal care (bathing/showering and mobility/toilet use), or additionally with a Score B- incontinence or problems eating, or a score C- all of these difficulties, assessed by a home-adapted Katz Index (Katz et al., 1963) or assessed by the residential-adapted Katz Index, scores A, B, or C (similar to the home version but considering additional criteria regarding disorientation in time and space) or $\mathrm{D}$ (dementia diagnostic);

- or having been diagnosed with dementia by a geriatrician, neurologist or psychiatrist (in the absence of a score on the residential-adapted Katz Index). The baseline data used reflected the "usual care" situation. Trained healthcare or social care professionals collected the data through interviews with disabled elderly persons and their main informal carers at home.

The InterRAI Home care instrument (interRAI HC) and an ad-hoc questionnaire (for social care service utilization and time spent by informal carers) were used. The interRAI HC instrument is an internationally validated and comprehensive geriatric assessment that provides a holistic evaluation of the main components of disability.

In complement, administrative data of the reimbursed healthcare consumption, routinely recorded, were used (individually matched with their Belgian national number between the two databases). For the municipality of the disabled older persons in our sample, the fiscal income per household and municipality was available (from StatBel, for the year 2013) and used as a proxy for socioeconomic status. Low income municipalities were identified as the first quartile municipalities with the lowest median fiscal income per household by using a representative sample of the older population in Belgium (provided by the national health care intermutualist agency). 
Stratification of the sample into different disability profiles

Disability profiles of older persons reflect the levels of long -term care needs and thus the level of support required. Disability is defined as "the difficulty or dependency in carrying out activities essential to independent living, including essential roles, tasks needed for self-care and living independently in a home, and desired activities important for one's quality of life" (Fried et al., 2004). To characterise degrees and types of disability, functional limitations on IADL and ADL, cognitive impairment (Salvador-Carulla and Gasca, 2010) and behavioural problems were considered. Indeed, persons with cognitive impairment are more likely to have a higher need of overall supervision due to their cognitive decline (Fox, Maslow and Zhang, 1999). Furthermore, they are less likely to receive help with IADL and ADL because of possible denial of their disability (Lavoie, 2000) or are less willing to be helped (Drennan, Cole and Iliffe, 2011). Only data with fully completed questionnaires on the variables of interest were included in the study. The Instrumental Activities of Daily Living Performance Scale (IADLP), the Activities of Daily Living Hierarchy Scale (ADLH) (Morris, Fries and Morris, 1999), the Cognitive Performance Scale (CPS) (Hartmaier et al., 1995; Morris et al., 1994), and the number of behavioural problems (inappropriate sexual behaviour, wandering, verbally aggressive, physically violent behaviour and inappropriate social behaviour) are the components used in the InterRAI HC to determine the disability profiles.

A Principal Component Analysis (PCA) was conducted, enabling explanatory variables to be on a unified scale (the scores of the following four scales measuring: functional limitations on IADL, ADL, cognitive performances and the number of behavioural problems) (Hastie, Tibshirani and Friedman, 2009). A clustering analysis was performed based on the PCA correlation matrix. A hierarchical algorithm (Ward algorithm) was used to define the number of groups which is a compromise between having similar individuals within a group, and having groups with important differences (Hastie, Tibshirani and Friedman, 2009), computed using the R package FactoMineR (Le, Josse and Husson, 2008). 
Disability profiles were described by the mean score compared to the scale cut-off. The cut-off is considered to be the threshold above which disability is significant: three (scale range 0-6) for the ADL Hierarchy scale; three (scale range 0-6) for the Cognitive Performance Scale; 24 (scale range 0-48) for the Performance Scale of IADL; and more than zero ( 0 and 5) number of behavioural problems.

\section{Stratification into presence levels of informal carer}

Formal and informal care are known to be highly interrelated (Balia and Brau, 2014; Bolin, Lindgren and Lundborg, 2008; Bonsang, 2009). Litwin showed that formal support utilisation depends on family relationship of the main informal carer (spouses, children) (Litwin and Attias-Donfut, 2009). Individual situations between spouses and children differ greatly on many characteristics: age, physical ability to help, time schedule's constraints, potential other caring responsibilities, ability to choose to get involved in the care of relatives, to delegate or to share tasks, motivations, their ability to cope with unexpected events or difficulties, etc. And for specific tasks such as intimate care, the willingness to provide help may also be significantly influenced by family relationship such as the gender considerations for children for parent intimate care (Evans, Coon and Crogan, 2007). Living arrangement of the main informal carer is also another important factor since co-residence with care recipient fosters the provision of help and overall a high level of involvement of informal carers (De Koker, 2009). Moreover, defining informal care also requires the distinction between non-cohabitant and cohabitant (Cès, De Almeida Mello, et al., 2017). Hence, we chose the living arrangement of the main informal carer as the second main determinant of the support. "No carer" was the third complementary modality, besides non-cohabitant and cohabitant. In addition, we did not expect an important discrepancy as children are mainly non-cohabitant and spouses, cohabitant. For children, becoming cohabitant may sometimes be decided after the loss of independence of older persons, for practical convenience. Nevertheless, such configuration is supposed to remain marginal due to practical constrains (space, location...) and possible financial incentives to live alone. 
The various home situations were defined by crossing the three disability profiles of the care recipient with the three presence levels of informal carer ( $\mathrm{N}=$ nine subgroups).

Confidence intervals were based on bootstrapping using bias-corrected and accelerated methods (5,000 replications of the same size as the original sample) (DiCiccio and Efron, 1996; Elliott and Payne, 2005). In our study, several subsamples of different sizes were created. Using a normal-based method for the sampling is not appropriate for subsamples of small size since the underlying nonnormal distribution of cost data. Hence, we chose to apply the bootstrap method for all subsamples, regardless the sample size, which allows accounting for positive skewness and heavy tails. The analysis was performed in R 'boot' package (Canty, 2017). The estimation of confidence intervals of cost differences were performed in Stata, SE 15.0 using a generalized linear model with a Gamma family distribution (appropriate for continuous, positive and skewed variables with variance being proportional to the square of the mean) and log link (the log function of the mean of the dependent variable is a linear combination of independent variables) (Mihaylova et al., 2011).

\section{Cost estimates of formal and informal support}

A micro-costing method was used to collect data (Frick, 2009; Tan et al., 2009). In addition to informal care costs, the cost of formal support used were presented as follows:

- $\mathrm{ADL}$ - IADL: nursing care (provided by a registered nurse), domestic help service, home care worker (domestic help and personal care), and meals-on-wheels ;

- equipment (hearing aids, glasses, orthoses...) and incontinence material (a yearly lump sum financed by NIHDI, €493.1 for disabled persons or $€ 160.9$ in 2016 for non-disabled persons and additionally, a minimum monthly cost estimate of $€ 100$ for incontinence material, for three diapers per day for the persons with at least once per day, incontinence problems for urine and/or faeces); 
- Health monitoring : personal alarm system, "care attendant" (a healthcare professional monitoring the health status at home) ; and medical care, including general practitioner and specialists (neurologist, neuropsychiatrists, psychiatrists, geriatrician);

- In-community respite services: day care (including reimbursed transportation costs) and short stays in a nursing home (less than 90 consecutive days);

The average costs per month, in euro (2016), were based on the consumption of the six-month period before baseline.

In the ad-hoc questionnaire, the intensity of informal care was retrospectively measured using time spent on caregiving over the past week and included the following tasks: Activities of Daily Living (personal hygiene care, incontinence management, eating, dressing, use of the toilet and mobility within the house), Instrumental Activities of Daily Living (meal preparation, medication, shopping, phone use, transportation, use of stairs and finance management) and supervision. For cohabitant informal carers, public commodities were excluded from the time measurement (shopping, household chores, finance management, and meal preparation) (Cès, de Almeida Mello, et al., 2017; van den Berg, Brouwer and Koopmanschap, 2004). The time spent by informal carers was valued using the replacement cost method (Paraponaris, Davin and Verger, 2012; van den Berg et al., 2006; van den Berg, Brouwer and Koopmanschap, 2004; Wubker et al., 2014). The valuation is performed according to the unit cost of the closest professional substitute. This estimation can be interpreted as the cost to support disabled elderly persons at home in the absence of informal carers. The hourly rate was the cost of home care services (for domestic tasks only or a home care worker), partially subsidized by the regions through a system of vouchers, €22.04 in 2016 (Schooreel and Valsamis, 2017). Time spent on caring was limited to 17 hours per day for several reasons (Quentin et al., 2010): some cohabitant carers reported that a high intensity of help was required. However, time use is less identifiable when sharing the same household, particularly when the patient has a high level of need, as time of supervision may actually include being on-call "in case of need" (e.g. 24 hours/day help was a recurrent answer). Furthermore, the daily capacity of carers to provide help (including supervision) is limited, as informal carers also 
have to perform their own basic ADL and IADL and need to sleep. We performed a sensitivity analysis of the cost estimates of informal care by using two methods- the opportunity cost method (OCM) and the contingent valuation method (CVM). The valuation principle of the OCM is to consider the costs of alternative activities that cannot be performed due to time spent on providing care. The value of the forgone activities is determined by the wages of informal carers, which is consistent with the theoretical analysis of labour supply (Chari et al., 2015; Posnett and Jan, 1996). We used the net average wage rate ( $€ 16$ per hour in 2015) for both persons employed and unemployed (Statbel, 2017). For unemployed persons under the age of 65, the minimum net wage rate of $€ 9.5$ per hour in 2016 (Eurostat) was used as a lower bound for reservation wages (Posnett and Jan, 1996; van den Berg et al., 2006). No information was available on their qualifications for approximating the reservation wage. Finally, for persons over the age of 65 , we considered opportunity costs to be not null. We used net retirement income ( $€ 11$ per hour in 2016) as an estimation of the displacement value of leisure activities and/or unpaid labour (Defeyt, 2017; ENEO, 2017). Furthermore, another scenario can be presented using the CVM; we used the value determined in the De Meijer study (€11.9, adjusted for 2016) that corresponds to the Willingness To Accept (WTA) to provide one additional hour of care. The WTA method is based on the assumption that an additional hour of care would require financial compensation since marginal costs are supposed to exceed marginal benefits. The value would represent the net difference between additional benefits and costs (van den Berg et al., 2005).

For social care services, "care attendants" (a skilled professional who monitors health status at home), services providing domestic help and home care workers (providing domestic help and basic hygiene care), the total number of hours worked over the past week were reported by respondents. The unit cost of the "care attendant" was $€ 30$ an hour, as a skilled professional (average hourly rate of nurse estimated in the pilot innovative health care projects). For meals-on-wheels, the frequency of meals per month was collected. The cost unit of meals was estimated by phone survey of a sample of organizations providing this service in Wallonia. The real cost is rarely known as there is no separated accounting for such 
services within organizations. Thus, the estimated unit cost was six euro a meal. Personal Alarm System (PAS) was valued for $€ 55$ per month (according to an average of different websites on PAS).

The accommodation cost of temporary stays in nursing homes, paid by the disabled elderly person, was valued at $€ 45.97$ per day (FOD-SPF economy, 2014). The cost estimation of day-care centres for care recipients has been valued at $€ 15$ per day (this cost varies between 10 and $€ 24$, according to a sample of day-care centre websites).

The costs of formal support were presented between:

- support funded by the NIHDI, and

- support funded by "other stakeholders" (Others): care recipients, informal carers, regions, sickness funds or private insurances.

Table 1 provides an overview of the different sources of the cost data: the quantity of resources used, cost units of these resources and funding stakeholders. 
TABLE 1 Overview of the data of resources used, cost units and funding stakeholders

\begin{tabular}{|c|c|c|c|c|c|c|c|c|c|}
\hline \multirow{3}{*}{\multicolumn{2}{|c|}{ Type of resources used }} & \multicolumn{3}{|c|}{ Cost data } & \multicolumn{5}{|c|}{ Funding stakeholders } \\
\hline & & \multirow[b]{2}{*}{ Unit } & \multirow[b]{2}{*}{ Unit cost } & \multirow{2}{*}{$\begin{array}{l}\text { Type of cost } \\
\text { estimation }\end{array}$} & \multirow{2}{*}{$\begin{array}{l}\text { Public health } \\
\text { insurance } \\
\text { (NIHDI) }\end{array}$} & \multirow[b]{2}{*}{ Clients } & \multirow{2}{*}{$\begin{array}{l}\text { Informal } \\
\text { carers }\end{array}$} & \multicolumn{2}{|c|}{ Other public stakeholders } \\
\hline & & & & & & & & Regions & Mutualities \\
\hline \multirow{8}{*}{$\begin{array}{l}\text { Health } \\
\text { care }\end{array}$} & Medical care & Medical care nomenclature & \multirow{3}{*}{ Variable } & \multirow{3}{*}{$\begin{array}{l}\text { Tariff and unit } \\
\text { routinely } \\
\text { recorded }\end{array}$} & $\mathrm{x}$ & Co- & \multirow{5}{*}{$\begin{array}{l}\text { Sharing } \\
\text { unknown }\end{array}$} & & \multirow{8}{*}{$\begin{array}{l}\text { Sharing } \\
\text { unknown }\end{array}$} \\
\hline & $\begin{array}{l}\text { Nursing care, } \\
\text { physiotherapy, } \\
\text { speech therapy, } \\
\text { health equipment }\end{array}$ & Health care nomenclature & & & $\mathrm{x}$ & $\begin{array}{c}\text { payments } \\
\text { (supplement } \\
\text { s not } \\
\text { collected) } \\
\end{array}$ & & & \\
\hline & \multirow{3}{*}{ Day care } & $\begin{array}{l}\text { Nomenclature of health care } \\
\text { provisions provided in day care and } \\
\text { transportation (reimbursed) }\end{array}$ & & & $\mathrm{x}$ & $\begin{array}{l}\text { Co- } \\
\text { payments }\end{array}$ & & $\begin{array}{c}\text { Tariff and unit } \\
\text { routinely recorded }\end{array}$ & \\
\hline & & $\begin{array}{l}\text { Number of days (for meals and } \\
\text { occupational activities) }\end{array}$ & $15 € /$ day & $\begin{array}{l}\text { Based on the } \\
\text { unit of volume } \\
\text { routinely } \\
\text { recorded }\end{array}$ & & $\mathrm{x}$ & & \multirow[t]{2}{*}{ Unknown } & \\
\hline & & Building & & & & & & & \\
\hline & \multirow{3}{*}{$\begin{array}{l}\text { Temporary stays } \\
\text { in nursing home }\end{array}$} & $\begin{array}{l}\text { Nomenclature of health care } \\
\text { provisions provided in nursing home }\end{array}$ & Variable & $\begin{array}{l}\text { Tariff and unit } \\
\text { routinely } \\
\text { recorded }\end{array}$ & & $\begin{array}{l}\text { Co- } \\
\text { payments }\end{array}$ & \multirow{2}{*}{$\begin{array}{l}\text { Sharing } \\
\text { unknown }\end{array}$} & $\begin{array}{l}\text { Tariff and unit } \\
\text { routinely recorded }\end{array}$ & \\
\hline & & Number of days (accommodation) & $45.97 € /$ day & $\begin{array}{l}\text { Based on the } \\
\text { unit of volume } \\
\text { routinely } \\
\text { recorded }\end{array}$ & & $\mathrm{x}$ & & Unknown & \\
\hline & & $\begin{array}{l}\text { Other cost components: buildings (no } \\
\text { unit per client) }\end{array}$ & & & & & & & \\
\hline \multirow{4}{*}{$\begin{array}{l}\text { Social } \\
\text { care }\end{array}$} & Home helper & Hours & \multirow{2}{*}{$22.04 €$} & \multirow{4}{*}{$\begin{array}{l}\text { Based on the } \\
\text { unit of volume } \\
\text { declared in the } \\
\text { ad-hoc } \\
\text { questionnaire }\end{array}$} & & $\mathrm{x}$ & \multirow{4}{*}{$\begin{array}{l}\text { Sharing } \\
\text { unknown }\end{array}$} & \multirow{4}{*}{ Sharing unknown } & \multirow{4}{*}{$\begin{array}{l}\text { Sharing } \\
\text { unknown }\end{array}$} \\
\hline & Housework help & Hours & & & & $\mathrm{x}$ & & & \\
\hline & Meal-on-wheels & Number of meals & $6 €$ & & & $\mathrm{x}$ & & & \\
\hline & Care attendant & Hours & $30 €$ & & & $\mathrm{x}$ & & & \\
\hline
\end{tabular}




\begin{tabular}{|l|l|c|c|c|c|c|c|}
\hline & $\begin{array}{l}\text { Personal alarm } \\
\text { system }\end{array}$ & Subscription & $55 \epsilon /$ month & & & $x$ & \\
\cline { 1 - 3 } $\begin{array}{l}\text { Informa } \\
\text { I care }\end{array}$ & $\begin{array}{l}\text { Time spent on } \\
\text { caring (excluding } \\
\text { travel time) }\end{array}$ & Hours & $22.04 /$ hours & & & & \\
\hline
\end{tabular}




\section{Results}

Profile of the care recipients and informal carers

The sample consisted of 5,642 disabled older persons, divided into nine subgroups according to the disability profiles and the presence levels of the informal carer. The individual characteristics of the disabled elderly and their main informal carer are presented in Table 2.

The three profiles of disability identified had the following characteristics:

- Persons in the group IADL ( $\operatorname{cogn}.),(\mathrm{N}=1,178)$ had significant limitations on performing IADL (average score $=32$ (range $0-48$ ), compared to the cut-off of 24). The average score of functional limitations on the ADL was low (average score= 1 (range 0-6), compared to the cut-off of 3). Finally, cognitive impairment was moderate (average $=2$ (range 0-6) on the CPS, compared to the cut-off of three). The average number of behavioural problems was low (0.2).

- Persons in the group Func. $(\mathrm{N}=2,595)$ had significant difficulties in performing IADL (average score $=34$, compared to the cut-off of 24). There were also significant limitations on the ADL (average score $=3$, equal to the cut-off of 3 ), while no cognitive impairment (average score $=0$ on the CPS, compared to the cut-off of 3 ) or behavioural problems were reported.

- Persons in the group Func. Cogn. $(\mathrm{N}=1,869)$ had significant difficulties in performing IADL (average score $=42$, compared to the cut-off of 24). They also had limitations on the ADL (average score $=3$, equal to the cut-off of 3), significant cognitive impairment (average score $=4$ on the CPS, compared to the cut-off of 3), and at least one behavioural problem, on average.

The distribution of the presence levels of the informal carer was similar between the two first profiles of disability, without significant cognitive impairment (58\% with a non-cohabitant carer, $27 \%$ 
with a cohabitant carer and $16 \%$ with no carer). In the group Func. Cogn., the proportion of persons helped by a cohabitant carer was much higher (57\%); 38 per cent of persons had a non-cohabitant carer, and only five per cent did not have an informal carer. The disability groups were built to be homogeneous. However, within groups, we observed that the average scores in functional limitations and cognitive impairment were higher in the situation with a cohabitant informal carer. The majority of care recipients were females, but within each disability profile, the proportion of females was lower in situations with a cohabitant informal carer (between $49 \%$ and 58\%). The proportion of care recipients living in municipalities with a low median fiscal income per household was lower in situations with an informal carer (between 6 and 15\%) than without one (26\% to 36\%).

The profiles of informal carers were different according to their living arrangement and confirmed our hypothesis on the link between living arrangement and family relationship. Non-cohabitant informal carers were, on average, younger (55 years) than cohabitant informal carers (69 years). Noncohabitant carers were primarily adult children of the recipient (between 78 and 82\%), while cohabitants were primarily spouses (74-75\%). Overall, the majority of non-cohabitant carers were also helped by at least one other informal carer (between 49 and 55\%), while cohabitant carers were slightly less often helped by another informal carer (between 38 and 42\%). The professional activity varied according to the living arrangement of the informal carer. Non-cohabitant carers had, primarily, a professional activity (62\%), while only 19 per cent of cohabitant carers worked professionally. 
TABLE 2. Profiles of the care recipients and informal carers

\begin{tabular}{|c|c|c|c|c|c|c|c|c|c|c|c|c|c|c|}
\hline & Age & Gender & Low inc. & Density & IADL & ADL & Cogn. & Nb. behav. & $\begin{array}{l}\text { Age } \\
\text { carer. }\end{array}$ & Child carer & Spouse carer & Prof.act. & $\begin{array}{c}\text { Nb carer. } \\
>1\end{array}$ & $\mathbf{N}$ \\
\hline & Mean & $\%$ & $\%$ & $\%$ & Mean & Mean & Mean & Mean & Mean & $\%$ & $\%$ & $\%$ & $\%$ & \\
\hline & 80 & 72 & 18.5 & 65.4 & 31.7 & 0.6 & 1.6 & 0.2 & - & - & - & - & - & 1178 \\
\hline & $79.5 / 80.4$ & $69.4 / 74.4$ & $16.4 / 20.8$ & $62.6 / 68$ & $31.3 / 32.1$ & $0.6 / 0.6$ & $1.5 / 1.6$ & $0.2 / 0.3$ & $-/-$ & $-/$ & - & $-/-$ & $-/-$ & \\
\hline \multirow[t]{2}{*}{$\begin{array}{r}\text { No informal } \\
\text { carer }\end{array}$} & 77.1 & 75 & 35.9 & 72.8 & 29.6 & 0.5 & 1.3 & 0.2 & - & - & - & - & - & 184 \\
\hline & $75.7 / 78.4$ & $67.4 / 80.4$ & $28.8 / 42.4$ & $65.8 / 78.3$ & $28.8 / 30.5$ & $0.4 / 0.6$ & $1.2 / 1.5$ & $0.1 / 0.3$ & $-/-$ & $-/-$ & $-/-$ & $-/-$ & $-/-$ & \\
\hline \multirow[t]{2}{*}{ Non-cohabitant } & 81.7 & 78 & 15.3 & 64.3 & 31.6 & 0.6 & 1.5 & 0.2 & 55.3 & 74.7 & 0.3 & 56.4 & 49.3 & 681 \\
\hline & $81.2 / 82.2$ & $74.6 / 80.9$ & $12.5 / 17.9$ & $60.6 / 67.8$ & $31.2 / 32.1$ & $0.6 / 0.7$ & $1.4 / 1.6$ & $0.1 / 0.2$ & $54.5 / 56.1$ & $71.2 / 77.8$ & $0 / 0.7$ & $52.4 / 60.3$ & $45.4 / 53$ & \\
\hline \multirow[t]{2}{*}{ Cohabitant } & 77.8 & 57.2 & 15.3 & 63.3 & 33 & 0.6 & 1.9 & 0.3 & 67.9 & 22 & 71.2 & 21.7 & 37.7 & 313 \\
\hline & 76.9/78.7 & $51.4 / 62.3$ & $11.5 / 19.2$ & $57.5 / 68.1$ & $32.2 / 33.7$ & $0.5 / 0.6$ & $1.8 / 2.1$ & $0.3 / 0.4$ & $66.2 / 69.5$ & $17.3 / 26.8$ & $65.5 / 75.7$ & $17.1 / 26.7$ & $32.3 / 42.8$ & \\
\hline \multirow[t]{2}{*}{ Func. } & 81 & 72.5 & 10.4 & 61.6 & 34.2 & 3.1 & 0.4 & 0 & - & - & - & - & - & 2595 \\
\hline & $80.7 / 81.3$ & $70.8 / 74.2$ & $9.3 / 11.6$ & $59.6 / 63.4$ & $34 / 34.5$ & $3.1 / 3.2$ & $0.4 / 0.4$ & $0 / 0.1$ & $-/-$ & $-/$ & $-/$ & $-/$ & $-/-$ & \\
\hline \multirow[t]{2}{*}{$\begin{array}{r}\text { No informal } \\
\text { carer }\end{array}$} & 80 & 75.1 & 25.6 & 65.4 & 32 & 3.2 & 0.3 & 0.1 & - & - & - & - & - & 433 \\
\hline & $79.2 / 80.8$ & $70.4 / 78.8$ & $21.5 / 29.8$ & $60.5 / 69.5$ & $31.3 / 32.7$ & $3.1 / 3.3$ & $0.2 / 0.4$ & $0 / 0.1$ & $-/-$ & $-/-$ & $-/-$ & $-/-$ & $-/-$ & \\
\hline \multirow[t]{2}{*}{ Non-cohabitant } & 82.4 & 78.4 & 5.7 & 62.3 & 33.8 & 3 & 0.4 & 0 & 55.6 & 77.2 & 0 & 61.9 & 54.6 & 1492 \\
\hline & $82 / 82.8$ & $76.1 / 80.4$ & $4.6 / 6.9$ & $59.9 / 64.7$ & $33.5 / 34.1$ & $2.9 / 3$ & $0.4 / 0.4$ & $0 / 0$ & $55.1 / 56.2$ & $75 / 79.2$ & $-/-$ & $59.2 / 64.4$ & $52 / 57$ & \\
\hline \multirow[t]{2}{*}{ Cohabitant. } & 78.7 & 57.9 & 11.2 & 57.6 & 36.6 & 3.4 & 0.5 & 0.1 & 68.6 & 21.5 & 71.2 & 20.2 & 37.8 & 670 \\
\hline & 78/79.3 & $54 / 61.5$ & 8.8/13.6 & $53.7 / 61.3$ & $36.1 / 37.1$ & $3.3 / 3.5$ & $0.4 / 0.5$ & $0 / 0.1$ & $67.4 / 69.7$ & $18.4 / 24.6$ & $67.5 / 74.5$ & $17 / 23.4$ & $34 / 41.5$ & \\
\hline \multirow[t]{2}{*}{ Func. cogn. } & 81 & 59 & 11.6 & 53.7 & 42.3 & 3.4 & 3.7 & 1.4 & - & - & - & - & - & 1869 \\
\hline & $80.6 / 81.3$ & $56.8 / 61.1$ & $10.1 / 13$ & $51.4 / 55.9$ & $42 / 42.6$ & $3.4 / 3.5$ & $3.7 / 3.8$ & $1.3 / 1.5$ & $-/-$ & $-/-$ & $-/-$ & $-/-$ & $-/-$ & \\
\hline \multirow[t]{2}{*}{$\begin{array}{r}\text { No informal } \\
\text { carer }\end{array}$} & 80.6 & 57 & 26 & 72 & 38.4 & 3.2 & 3.3 & 1.1 & - & - & - & - & - & 100 \\
\hline & $78.4 / 82.6$ & $46 / 66$ & $17 / 34$ & $62 / 79$ & $36.6 / 39.8$ & $3 / 3.4$ & $3 / 3.5$ & $0.8 / 1.7$ & $-/-$ & $-/-$ & $-/-$ & $-/-$ & $-/-$ & \\
\hline
\end{tabular}




\begin{tabular}{rcccccccccccccc} 
Non-cohabitant & 83.5 & 73.6 & 10.2 & 51.2 & 40.7 & 3.2 & 3.4 & 1.1 & 55.3 & 75.5 & 0 & 58 & 53.5 & 707 \\
& $82.9 / 84$ & $70 / 76.5$ & $7.9 / 12.3$ & $47.5 / 54.7$ & $40.2 / 41.2$ & $3.2 / 3.3$ & $3.4 / 3.5$ & $1 / 1.3$ & $54.5 / 56.2$ & $72.1 / 78.4$ & $-/-$ & $54.2 / 61.8$ & $49.5 / 57$ & \\
Cohabitant & 79.3 & 49.5 & 11.1 & 53.6 & 43.8 & 3.6 & 4 & 1.5 & 69.2 & 19.7 & 72.1 & 16.8 & 42.3 & 1062 \\
& $78.8 / 79.8$ & $46.5 / 52.4$ & $9.3 / 13.1$ & $50.4 / 56.3$ & $43.5 / 44.1$ & $3.5 / 3.7$ & $3.9 / 4$ & $1.4 / 1.7$ & $68.3 / 70$ & $17.3 / 22.1$ & $69.2 / 74.6$ & $14.6 / 19.3$ & $39.3 / 45.2$ & \\
\hline
\end{tabular}

Note: CI : Confidence Interval, Low inc.: low income municipalities, Cogn.: cognitive impairment, Nb. behav.: number of behavioural problems, Prof. act.: professional activity, Nb. carers: number of informal carers, $\mathrm{N}$ : total number of disabled older persons 


\section{The cost of support (per person/month)}

The results on costs are presented in Table 3 per group of disability and per level of presence of informal carer. In Table 4, cost differences of formal support between the different profiles of disability and the presence level of informal carer are presented.

In the group IADL (cogn.), the average total cost of home support was $€ 2,458.6$ [CI 2,277; 2,665], including the cost of informal care. The average cost of informal care was higher in situations with a cohabitant carer, $€ 4,164 /$ month, [CI 3,640.7; 4,794.4] compared with a non-cohabitant carer, $€ 1,084$ [CI 977.2; 1,232.5].

The average total cost of formal support was $€ 725$ [CI 686.5; 766.9] in this disability group. This cost was significantly lower in situations with a cohabitant carer, $€ 562$ [CI 499.4; 639.2], than with a non-cohabitant carer (average difference: -209.1 [CI -297.4; -120.8]) or with no carer (average difference: -271.8 [CI -407.4; -136.1]).

- For the NIHDI, the average total costs was $€ 192.1$ (there was no significant difference between the presence levels of informal carer).

- For other funding stakeholders, the average total cost of formal support was significantly lower in situations with a cohabitant carer $€ 377.9$ [CI 325.6; 442.2] than in situations without one $€ 598.7$ [CI 513.4; 704.9] (average difference: -220.9, [CI -330.1; -111.6]) and in situations with a non-cohabitant carer, $€ 587$ [CI 543.6; 638.8] (average difference: 209.19, [CI -283.74; -134.64]). This difference was mainly due to the cost of home care services not paid by the NIDHI (domestic help, home care worker, meals-on-wheels) which was lower in situations with a cohabitant carer, €301 [CI 257.8 ; 352.1] than in the situations without a carer, $€ 523$ [CI $444.5 ; 617.6]$ or with a non-cohabitant carer, $€ 496[\mathrm{CI}$ $458.1 ; 536.9]$. 
In the group Func., the total cost of the home support was $€ 2,976$ [CI 2,834.5; 3,130.8], including informal care costs. The average cost of informal care was much higher in situations with a cohabitant carer, $€ 5,251.1$ [CI 4,854.6; 5,703.3] than with a non-cohabitant carer, €1,086.5 [CI 1003.9; 1185.2].

The average total cost of formal services was €995.5 [CI 960.2; 1035.7], which was not significantly different between the three presence levels of the informal carer.

- For the NIHDI, the average total cost was $€ 406.7$ and varied according to the presence levels of the informal carer. It was significantly higher in situations with a cohabitant informal carer, $€ 548.2$ [CI 501.3; 597.9) than in groups with a non-cohabitant carer, $€ 356.6[\mathrm{CI}$ 335.8; 379.2] (average difference: 191.58, [CI 138.14; 245.03]) and without a carer, €360.2 [CI 318.8; 414.1] (average difference: 188, [CI 119.9; 256.2]).

- For other funding stakeholders, the total average cost was $€ 588.9$ [CI 561.9; 619.4] and varied according to the presence levels of the informal carer. It was significantly lower in the group with a cohabitant carer, $€ 453.9$ [CI 413.4; 499.7] than in situations with a noncohabitant carer €653.5 [CI 616.4; 696.7] (average difference: -199.6, [CI -258.9; -140.3]) and without one, €575 [CI 515.9; 648.3], (difference -121.38, [CI-199.8; -43]).

In the group Func. Cogn., the total cost of home support was $€ 6,692.2$ [CI $6,419.4 ; 6,959.9]$ per person/month, including informal care costs.

The average cost of informal care was much higher in situations with a cohabitant carer, $€ 7,932$ [CI 7,535.5; 8,306.9] than with a non-cohabitant carer, €2,223.8 [CI 2,008.9; 2,480.3]).

The average total cost of formal services was $€ 1,343.9$ [CI 1,292.9; 1,398.1] but varied significantly according to the presence levels of the informal carer. In situations with a cohabitant carer, the average cost was significantly lower, $€ 1,246.4[1,181.5 ; 1,313.2]$, than in situations with a non-cohabitant carer, $€ 1,506.8$ [CI 1,416.3; 1,608.1] (average difference: -260.3 [CI -376.7; -143.9]). Finally, the average cost in situations with a non-cohabitant carer was significantly higher than without one, $€ 1,227.6$ [CI 1,063.6; 1,413.5] (average difference: 279.1 [CI 78.6; 479.6]). 
- For the NIHDI, the average total cost was $€ 571.7$ [CI 543.7; 601] and no significant differences were observed according to the presence levels of the informal carer.

- For the other funding stakeholders, the average total cost was significantly lower in situations with a cohabitant carer, $€ 648.5$ CI $[603.2 ; 699.5]$ than with a non-cohabitant carer, €964 [CI 886.6; 1,047.8] (average difference: 315.59 [CI -407.9; -223.3]). The average cost in situations with a non-cohabitant carer was also significantly higher than with no carer, $€ 730$ [CI 600; 887.3] (average difference: 233.82, [CI 69.64; 398.01]). The cost of home care services not paid by the NIHDI (domestic help, meals on wheels and home care workers) was significantly lower with a cohabitant carer, €430 [CI 396.2; 466.8] than in the two other situations, with a non-cohabitant carer, €726 [CI 669.4; 788.2] or with no carer €624 [CI 506.8; 760.2]. 
TABLE 3. Average costs of health care and long-term care services used by disabled elderly persons and informal care (per month, per person)

\begin{tabular}{|c|c|c|c|c|c|c|c|c|c|c|c|c|c|}
\hline & \multirow{2}{*}{ Informal care } & \multicolumn{2}{|c|}{ ADLs-IADLs } & \multicolumn{2}{|c|}{$\begin{array}{c}\text { Rehab. } \\
\text { (physio., equip.) }\end{array}$} & \multicolumn{2}{|c|}{$\begin{array}{c}\text { Health monitoring } \\
\text { (PAS, care assis., medical care) }\end{array}$} & \multicolumn{2}{|c|}{$\begin{array}{l}\quad \text { In-community respite } \\
\text { (day care, nursing home short } \\
\text { stays) }\end{array}$} & \multicolumn{3}{|c|}{ Total cost of formal senvices } & \multirow[b]{2}{*}{ Total } \\
\hline & & $\begin{array}{l}\text { Other } \\
\text { (home } \\
\text { care) }\end{array}$ & $\begin{array}{c}\mathrm{NIHDI} \\
\text { (Nursing care) }\end{array}$ & $\begin{array}{l}\text { Othe } \\
r\end{array}$ & $\mathrm{NIHDI}$ & Other & $\begin{array}{c}\mathrm{NIHDI} \\
\text { (medical care) }\end{array}$ & Other & Regions & Other & NIHDI. & Total & \\
\hline $\begin{array}{r}\text { IADL (cogn.) } \\
\mathrm{Cl}\end{array}$ & $\begin{array}{c}1733.2 \\
1559.6 / 1934.8\end{array}$ & $\begin{array}{c}448.4 \\
420.5 / 48 \\
0.1\end{array}$ & $\begin{array}{c}116.7 \\
104.6 / 130.3\end{array}$ & $\begin{array}{c}9 \\
7.2 / \\
11.8\end{array}$ & $\begin{array}{c}40.2 \\
35.2 / 46.4\end{array}$ & $\begin{array}{c}48.3 \\
36.8 / 67.7\end{array}$ & $\begin{array}{c}35.2 \\
33 / 37.6\end{array}$ & $\begin{array}{c}11.8 \\
8.7 / 16.2\end{array}$ & $\begin{array}{c}15.7 \\
11.6 / 21.8\end{array}$ & $\begin{array}{c}533.3 \\
500.2 / 570.1\end{array}$ & $\begin{array}{c}192.1 \\
176.9 / 209.1\end{array}$ & $\begin{array}{c}725.4 \\
686.5 / 766.9\end{array}$ & $\begin{array}{c}2458.6 \\
2277 / 2665\end{array}$ \\
\hline $\begin{array}{r}\text { No informal carer } \\
\qquad \mathrm{Cl}\end{array}$ & $\begin{array}{l}0 \\
-1-\end{array}$ & $\begin{array}{c}523.2 \\
444.5 / 61 \\
7.6\end{array}$ & $107 / 184.8$ & $\begin{array}{l}5.6 \\
4.1 / \\
7.9\end{array}$ & $38.7 / 84.3$ & 20.2/92.1 & $34.2 / 50$ & $6.8 / 31.4$ & $7.7 / 34.3$ & $\begin{array}{c}598.7 \\
513.4 / 704.9\end{array}$ & $\begin{array}{c}235.1 \\
188.8 / 309.8\end{array}$ & $\begin{array}{c}833.8 \\
728.7 / 955.4\end{array}$ & $\begin{array}{c}833.8 \\
725.2 / 964\end{array}$ \\
\hline $\begin{array}{r}\text { Non-cohabitant } \\
\mathrm{Cl}\end{array}$ & $\begin{array}{c}1084.4 \\
977.2 / 1232.5\end{array}$ & $\begin{array}{c}496 \\
458.1 / 53 \\
6.9\end{array}$ & $100.3 / 130.3$ & $\begin{array}{l}9.6 \\
6.7 / \\
14.4\end{array}$ & $\begin{array}{c}33.3 \\
28.4 / 39.3\end{array}$ & $36.5 / 77.7$ & 36.7 & 12.6 & $11.6 / 27.4$ & $\begin{array}{c}587.1 \\
543.6 / 638.8\end{array}$ & $\begin{array}{c}184.1 \\
166.9 / 203.8\end{array}$ & $\begin{array}{c}771.2 \\
720.3 / 826.6\end{array}$ & $\begin{array}{c}1855.6 \\
1736.2 / 2020.8\end{array}$ \\
\hline Cohabitant & $\begin{array}{c}4163.8 \\
3640.7 / 4794.4\end{array}$ & $\begin{array}{c}301 \\
257.8 / 35 \\
2.1\end{array}$ & $\begin{array}{c}108.7 \\
85.2 / 141.7\end{array}$ & $\begin{array}{l}9.8 \\
7.5 / \\
14.5\end{array}$ & $\begin{array}{c}46.7 \\
37.2 / 58.8\end{array}$ & $\begin{array}{c}47.9 \\
28.1 / 100 . \\
9\end{array}$ & $\begin{array}{c}28.8 \\
25.9 / 32.3\end{array}$ & $\begin{array}{c}7.9 \\
4.1 / 15.7\end{array}$ & $\begin{array}{c}11.3 \\
6.3 / 20.1\end{array}$ & $\begin{array}{c}377.9 \\
325.6 / 442.2\end{array}$ & $\begin{array}{c}184.2 \\
152.9 / 221.9\end{array}$ & $\begin{array}{c}562 \\
499.4 / 639.2\end{array}$ & $\begin{array}{c}4725.8 \\
4170.8 / 5335.9\end{array}$ \\
\hline Func. & $\begin{array}{c}1980.5 \\
1841.7 / 2125.3\end{array}$ & $\begin{array}{c}478.4 \\
457.6 / 50 \\
2.5\end{array}$ & $268.5 / 299.5$ & $\begin{array}{c}12.9 \\
11.5 \\
/ 14 . \\
6\end{array}$ & $75.6 / 89.5$ & $46.8 / 73.2$ & $40.4 / 43.7$ & $14.3 / 20.4$ & $18.9 / 27.2$ & 561.9/619.4 & $387.9 / 426.9$ & 995.5 & 2976 \\
\hline No informal carer & $-1-$ & $\begin{array}{c}469.9 \\
423.2 / 52 \\
3.3\end{array}$ & $210.9 / 285.7$ & $\begin{array}{c}14 \\
10.5 \\
/ 21 . \\
7\end{array}$ & $62.9 / 95.8$ & $25 / 119.4$ & $36.3 / 45.1$ & $14.3 / 30.9$ & $17 / 36.4$ & $515.9 / 648.3$ & $318.8 / 414.1$ & $\begin{array}{c}935.4 \\
855.4 / 1029.8\end{array}$ & $854.7 / 1030.7$ \\
\hline Non-cohabitant & 1003.9/1185.2 & 530.7 & 236.1/272.1 & $\begin{array}{c}10.6 \\
9.1 / \\
13\end{array}$ & $53.4 / 64.7$ & $56.7 / 95.2$ & $42.3 / 46.9$ & $13.9 / 21.8$ & $18 / 28.2$ & $616.4 / 696.7$ & $335.8 / 379.2$ & $\begin{array}{c}1010.1 \\
961.5 / 1063.7\end{array}$ & 1995/2210.1 \\
\hline Cohabitant & $\begin{array}{c}5251.1 \\
4854.6 / 5703.3\end{array}$ & $\begin{array}{c}367.6 \\
334.2 / 41 \\
0.7\end{array}$ & $337.8 / 412.6$ & $\begin{array}{c}17.1 \\
14.7 \\
/ 20 . \\
6\end{array}$ & 119.9/160.7 & $22.6 / 55.5$ & $34.5 / 40.2$ & $9.4 / 20.9$ & $14 / 32.4$ & $413.4 / 499.7$ & $\begin{array}{c}548.2 \\
501.3 / 597.9\end{array}$ & $\begin{array}{c}1002.1 \\
937.5 / 1076.4\end{array}$ & $\begin{array}{c}6253.2 \\
5822.5 / 6712.7\end{array}$ \\
\hline Func. Cogn. & 5348.3 & 552.3 & 439 & 14.4 & 95.5 & 118.7 & 37.1 & 32.2 & 54.7 & 772.2 & 571.7 & 1343.9 & 6692.2 \\
\hline
\end{tabular}




\begin{tabular}{|c|c|c|c|c|c|c|c|c|c|c|c|c|c|}
\hline $\mathrm{Cl}$ & $5087 / 5637.1$ & $\begin{array}{c}520.8 / 58 \\
6\end{array}$ & 415.7/463.1 & $\begin{array}{c}12.8 \\
/ 16 . \\
4\end{array}$ & 88.4/103.1 & $\begin{array}{c}99.7 / 144 . \\
5\end{array}$ & $35.4 / 39.1$ & $28.2 / 37$ & $47.4 / 62.8$ & $732.2 / 816.6$ & $543.7 / 601$ & 1292.9/1398.1 & 6419.4/6959.9 \\
\hline $\begin{array}{r}\text { No informal carer } \\
\qquad \mathrm{Cl}\end{array}$ & $\begin{array}{l}0 \\
-1\end{array}$ & $\begin{array}{c}624.1 \\
506.8 / 76 \\
0.2\end{array}$ & $301.7 / 484.7$ & $\begin{array}{c}16.8 \\
10 / 3 \\
6.1\end{array}$ & $\begin{array}{c}75 \\
54.6 / 105.1\end{array}$ & $\begin{array}{c}49.6 \\
28.1 / 105 . \\
6\end{array}$ & $31.8 / 50.3$ & $8.2 / 40.9$ & $6.4 / 58.1$ & $\begin{array}{c}730.2 \\
600 / 887.3\end{array}$ & $\begin{array}{c}497.3 \\
408 / 625.2\end{array}$ & $\begin{array}{c}1227.6 \\
1071 / 1425.7\end{array}$ & $\begin{array}{c}1227.6 \\
1063.6 / 1413.5\end{array}$ \\
\hline $\begin{array}{r}\text { Non-cohabitant } \\
\qquad \mathrm{Cl}\end{array}$ & 2223.8 & $\begin{array}{c}726 \\
669.4 / 78 \\
8.2\end{array}$ & $\begin{array}{c}427.9 \\
393.7 / 467.4\end{array}$ & $\begin{array}{c}12.7 \\
10.4 \\
/ 15 . \\
9\end{array}$ & $64.4 / 81.8$ & $\begin{array}{c}148.2 \\
111 / 207 . \\
8\end{array}$ & $\begin{array}{c}42.9 \\
39.8 / 46.5\end{array}$ & $23.3 / 37.3$ & 47.7 & $\begin{array}{c}964.1 \\
\\
886.6 / 1047 \\
8\end{array}$ & $\begin{array}{c}542.7 \\
500.8 / 585.9\end{array}$ & $\begin{array}{c}1506.8 \\
1416.3 / 1608.1\end{array}$ & 3730.5 \\
\hline Cohabitant & $\begin{array}{c}7932 \\
7535.5 / 8306.9\end{array}$ & $\begin{array}{c}429.8 \\
396.2 / 46 \\
6.8\end{array}$ & $\begin{array}{c}451.8 \\
419.7 / 486.2\end{array}$ & $\begin{array}{c}15.3 \\
13.3 \\
/ 18 . \\
2\end{array}$ & $102.5 / 125.4$ & $\begin{array}{c}105.5 \\
\\
84.9 / 133 . \\
6\end{array}$ & 33 & $\begin{array}{c}35.2 \\
29.5 / 41.9\end{array}$ & $\begin{array}{c}62.6 \\
53 / 74.3\end{array}$ & $\begin{array}{c}648.5 \\
603.2 / 699.5\end{array}$ & $\begin{array}{c}598 \\
558.3 / 641.9\end{array}$ & $\begin{array}{c}1246.4 \\
1181.5 / 1313.2\end{array}$ & $\begin{array}{c}9178.4 \\
8788.6 / 9574.4\end{array}$ \\
\hline
\end{tabular}

Note: CI: Confidence Interval, PAS: Personal Alarm System 
TABLE 4. Cost differences of formal support between the different profiles of disability and the presence level of informal carer

\begin{tabular}{|c|c|c|c|c|}
\hline & & $\begin{array}{l}\text { Mean difference of cost for the } \\
\text { other stakeholders }\end{array}$ & $\begin{array}{l}\text { Mean difference of cost } \\
\text { for the NIHDI }\end{array}$ & Mean difference of formal cost \\
\hline Costffur & tional ) - Cost(IADL (cogn.)) & 55.57 & 214.58 & 270.16 \\
\hline & & $10 . / 3 / 100.41$ & & 215.24 / 325.08 \\
\hline  & tional and coonitive ) - Cost(functional) & 183.36 & 165.00 & 348.36 \\
\hline & & $133.02 / 233.70$ & 130.27 / 199.73 & $283.26 / 413.45$ \\
\hline & Cost(non-cohabitant) - Cost(no carer) & $\begin{array}{c}-11.66 \\
-115.54 / 92.21\end{array}$ & $\begin{array}{c}-50.93 \\
-110.96 / 9.09\end{array}$ & $\begin{array}{c}-0.07 \\
-0.23 / 0.07\end{array}$ \\
\hline $\begin{array}{l}\text { IADL } \\
\text { (cogn.) }\end{array}$ & Cost(cohabitant) - Cost(non-cohabitant) & $\begin{array}{c}-209.19 \\
-283.74-134.64 \\
\end{array}$ & $\begin{array}{c}0.04 \\
-38.84 / 38.93 \\
\end{array}$ & $\begin{array}{c}-209.13 \\
-297.42 /-120.85 \\
\end{array}$ \\
\hline & Cost(cohabitant) - Cost(no carer) & $\begin{array}{c}-220.86 \\
-330.07 /-111.64 \\
\end{array}$ & $\begin{array}{c}-50.89 \\
-117.73 / \quad 15.94\end{array}$ & $\begin{array}{c}-271.77 \\
-407.45 /-136.10\end{array}$ \\
\hline & Cost(non-cohabitant) - Cost(no carer) & $\begin{array}{c}78.22 \\
1.29 / 155.15 \\
\end{array}$ & $\begin{array}{c}-3.56 \\
-55.58 / 48.46 \\
\end{array}$ & $\begin{array}{c}0.07 \\
-.029 / 0.18 \\
\end{array}$ \\
\hline Func. & Cost(cohabitant) - Cost(non-cohabitant) & $\begin{array}{c}-199.61 \\
-258.87 /-140.34 \\
\end{array}$ & $\begin{array}{c}191.58 \\
138.14 / 245.03 \\
\end{array}$ & $\begin{array}{c}-7.99 \\
-94.12 / 78.13\end{array}$ \\
\hline & Cost(cohabitant) - Cost(no carer) & $\begin{array}{c}-121.38 \\
-199.76 /-43.00 \\
\end{array}$ & $\begin{array}{c}188.02 \\
119.88 / 256.16 \\
\end{array}$ & $\begin{array}{c}66.66 \\
-45.17 / 178.49 \\
\end{array}$ \\
\hline & Cost(non-cohabitant) - Cost(no carer) & $\begin{array}{c}233.82 \\
69.64 / 398.01\end{array}$ & $\begin{array}{c}45.342 \\
-69.84 / 160.52\end{array}$ & $\begin{array}{c}279.13 \\
78.62 \quad 479.65\end{array}$ \\
\hline $\begin{array}{l}\text { Func. } \\
\text { Cogn. }\end{array}$ & Cost(cohabitant) - Cost(non-cohabitant) & $\begin{array}{c}-315.59 \\
-407.87 /-223.31\end{array}$ & $\begin{array}{c}55.29 \\
-3.27 / 113.85\end{array}$ & $\begin{array}{c}-260.28 \\
-376.66 /-143.91\end{array}$ \\
\hline & Cost(cohabitant) - Cost(no carer) & $\begin{array}{c}-81.76 \\
-233.49 / 69.96\end{array}$ & $\begin{array}{c}100.63 \\
-13.94 / 215.20\end{array}$ & $\begin{array}{c}18.85 \\
-170.01 / 207.71\end{array}$ \\
\hline
\end{tabular}

Note: CI: Confidence Interval, statistics: univariate GLM model, Gamma family, log link 
In Figure 1, the average total monthly costs of support per funding stakeholder are presented. Informal care costs are sub-divided by time: up to eight hours per day and between eight and 17 hours. In the group Func. Cogn., the cost of informal care between eight and 17 hours accounted for almost half of the average total cost of informal care, while in the two other disability groups, it was about 30 per cent of the average cost.

Figure 1. Average total costs (per month/per client).

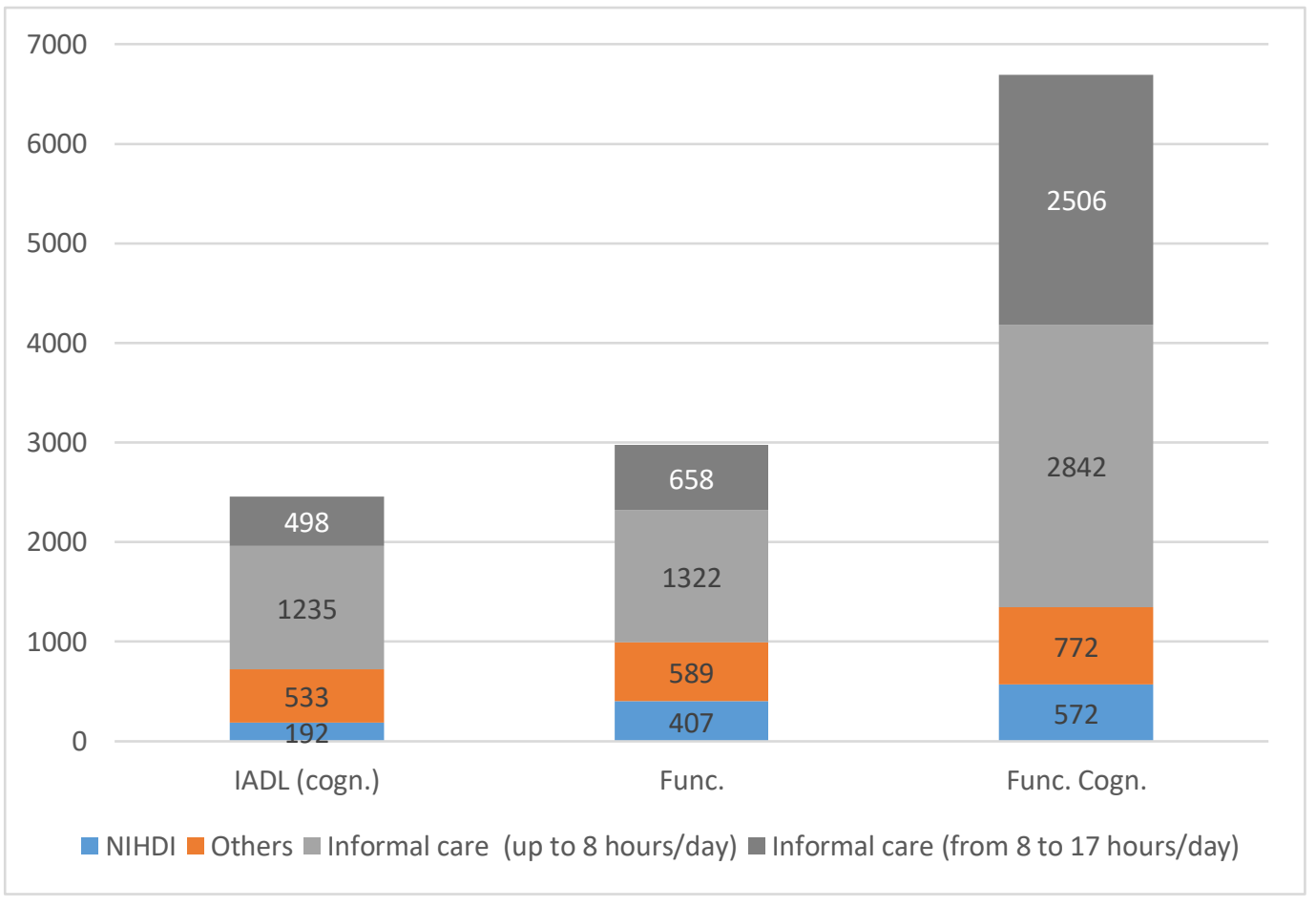

Cost distributions were highly skewed. Thus, box plots, presented in figures 1,2 and 3, were useful to show the overall low levels of use of formal support through the first quartile values and medians, according to the presence levels of an informal carer in the two disability groups with significant functional limitations (with or without cognitive impairment). The box represents the three quartiles: the lower part of the box indicates the first quartile, i.e. $25 \%$ of the persons have a lower cost than this amount, the upper part of the box indicates the third quartile (25\% of the persons have a higher cost than this amount) with in-between, the median cost (outside the box, the two whiskers indicate the largest value and the lowest value determined as: quartile $+/-1.5^{*}$ the interquartile range). In order to 
improve the readability of the graphs, the outliers values (defined as above the largest value) were removed.

In the group Func.:

- The total cost of formal support was below $€ 353$ per month for 25 per cent of the persons. No differences were observed according to presence level of the informal carer.

- For the NIHDI, the level of the first quartile was low: between 26 and $€ 56$ per month. Medians remained below $€ 400$ per month.

- For other stakeholders, the level of the first quartile was also low: between 33 (with a cohabitant carer) and $€ 180$ per month (with a non-cohabitant carer). Overall, we observed that the medians remained below $€ 600$ in all three presence levels of an informal carer.

In the group Func. Cogn.:

- For 25 per cent of persons, the total cost of formal support was below $€ 382$ per month in situations with a cohabitant carer, $€ 531$ with no carer and $€ 631$ with a non-cohabitant carer.

- The cost for the NIHDI remained at a low level for half of the persons in this group: overall, the medians were below $€ 400$ per month, and the first quartile was between 49 and $€ 116$ per month.

- For other stakeholders, the cost also remained low for a large proportion of the persons in this disability group: the median was below $€ 600$ per month, and the first quartile varied between 57 (with a cohabitant carer) and $€ 253$ per month (with a non-cohabitant carer). 
Figure 2. Total cost distributions of formal support (per person/month, values of the first quartiles displayed, outliers are not displayed).

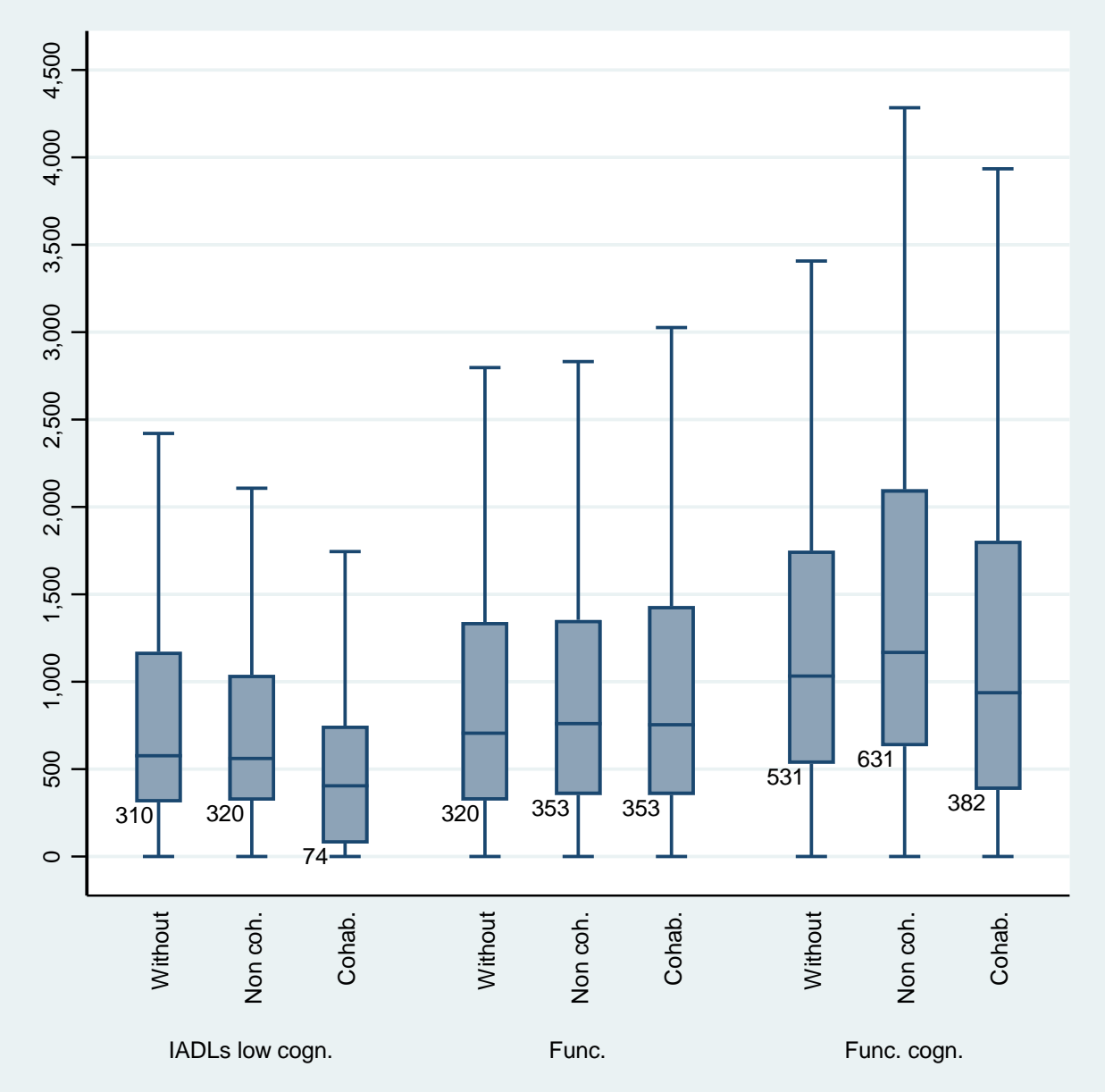


Figure 3. Total cost distributions for the NIHDI (per person/month, values of the first quartiles displayed, outliers are not displayed).

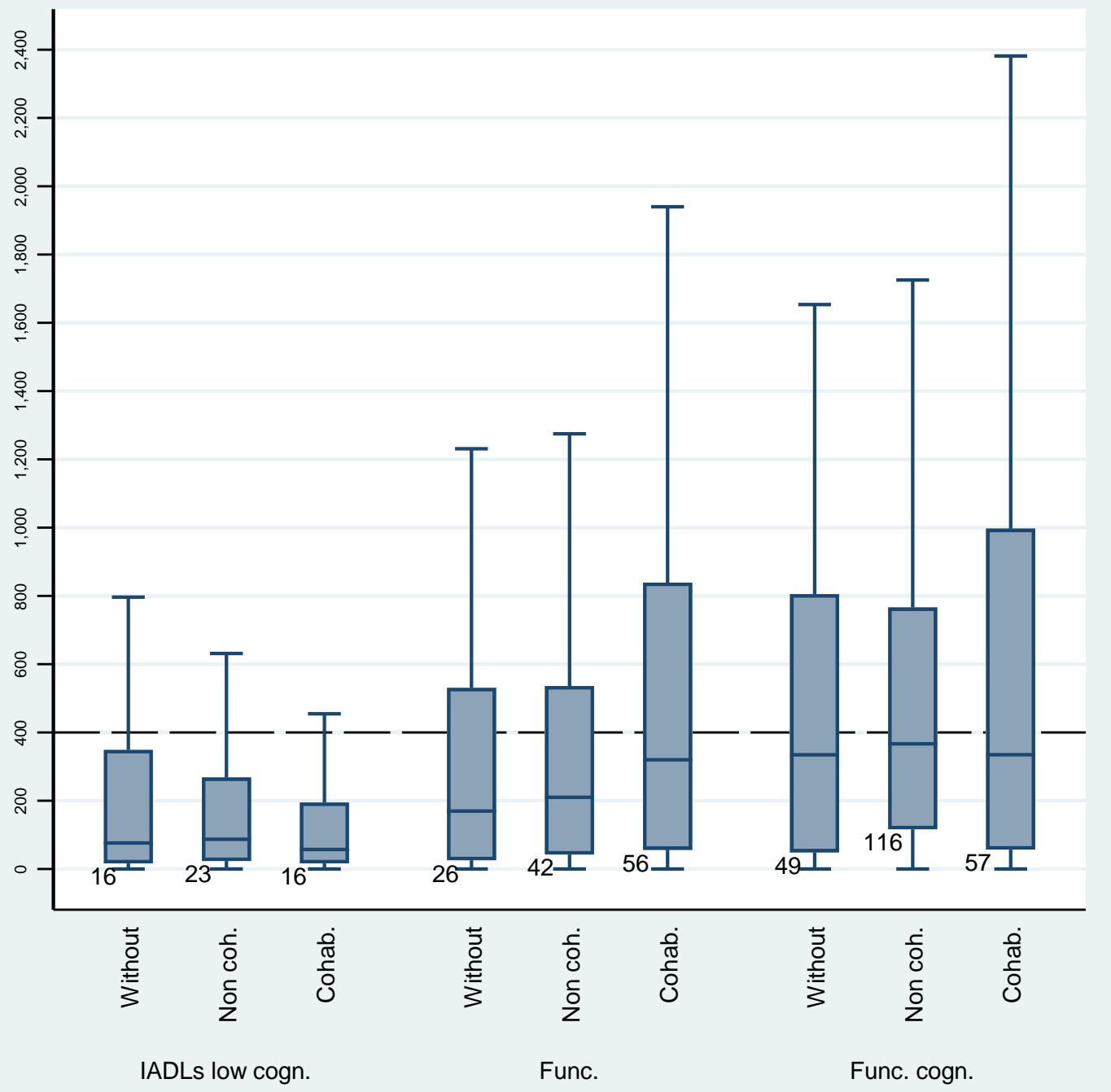


Figure 4. Total cost distributions for other stakeholders (per person/month, values of the first quartiles displayed, outliers are not displayed).



\section{Discussion}

The aim of the study was to estimate the direct costs of formal and informal support currently provided at home in Belgium, per disability profile and presence levels of the main informal carer.

The results show that the disability criteria used were significant determinants of cost of informal and formal support for both the NIHDI and other stakeholders. Cognitive impairment is a significant factor influencing the cost of home support for disabled older persons, as shown in other studies on dementia (Quentin et al., 2010; Schwarzkopf et al., 2011; Taylor Jr et al., 2001). Persons with 
cognitive impairment required more supervision outside the moments dedicated to IADL and ADL. Such result is also showed by the high proportion of cohabitant carers in this group: i.e. the persons are more likely to need constant supervision. In a qualitative study, cohabitant carers who help persons with cognitive impairment reported the important negative impact on their life with the impossibility to go out (Cès, Flusin, et al., 2017).

The comparison of our results with previous studies is difficult to perform because of the diversity of methods (perspective, cost components, definition of informal care, target population, etc.) (Quentin et al., 2010) and lack of studies on disability of older persons living at home.

In our sample, a large majority of disabled elderly persons were supported by at least one informal carer. Only five per cent of persons in the group with the highest level of disability and 16-17 per cent of persons in the two other groups of disability had no informal carer. Similar figures were observed in France for disabled older persons with at least three different needs of help on the IADL and ADL (Paraponaris, Davin and Verger, 2012). In our study, in the three disability groups, the cost of informal care accounted for more than half of the total cost of the support. For the group IADL (cogn.), informal care cost represented 70 per cent of the total cost of support. In the group Func., 66 per cent while this number was as high as 80 per cent for the group Func. Cogn. This is in line with previous studies on dementia (Quentin et al., 2010; Schwarzkopf et al., 2011). In France, the cost of informal care provided to disabled older persons was estimated to be half of the total cost of support (Paraponaris, Davin and Verger, 2012). In our study, this cost component was highly dependent on the living arrangement of the carer: between 1,084 and $€ 2,223$ for non-cohabitant carers, and between 4,163 and $€ 7,932$ for cohabitant carers. The share of the informal care cost, based on living arrangements, varied between 51 and 60 per cent for non-cohabitant carers, and 84 to 88 per cent for cohabitant carers (according to the disability profiles). These results were in line with the observations of De Koker in Flanders (De Koker, 2009) that co-residence allowed more intensive informal care. Overall, using either the OCM or CVM leads to lower cost estimates of informal care. Informal care costs for non-cohabitant carers represented between 36 and $46 \%$ of the total cost, while in situations with a cohabitant carer, the proportion remained high (about $70-78 \%$ of the total cost). 
Concerning only the cost of formal support, other stakeholders were the main funding body. They accounted for more than half of the total cost of formal support in the three disability groups (between $57 \%$ and $74 \%$ ) and were always significantly lower in situations with a cohabitant carer. Hence, the NIHDI did not finance the main part of formal home support costs, even in the highest level of disability group. This result may be partially due to low costs of various healthcare services that support the disabled elderly at home: nursing care, physiotherapy and speech therapy. At home, the average costs of these similar services were much lower than in nursing homes. In our sample, these average costs, per person/month were $€ 166$ in the group IADL (cogn.), $378 €$ in the group Func. and $€ 517$ in the group Func. Cogn.. In contrast, in nursing homes, such healthcare services had an average total cost of $€ 1,632$ per resident in Belgium in 2017 (unpublished statistics provided by the NIHDI, for all disability profiles in nursing homes). The public funding of nursing home beds is based on a case-mix system determined by disability profiles of residents and the number of health care staff (Van den Bosch et al., 2011). Hence, according to the average cost of formal support at home, reimbursed long-term healthcare services are much less provided at home than in nursing homes.

A deeper analysis revealed that cost sharing for the NIHDI was slightly higher in situations with a cohabitant carer because of the lower use of home care services (domestic help, home care worker and meals-on-wheels). This result is consistent with the hypothesis that cohabitant carers are a substitute to home care services. In the group with functional limitations, the savings of home care services almost compensated the higher costs observed for the NIHDI. This can be explained by a higher cost for personal nursing care because of a higher level of functional limitations of care recipients with a cohabitant carer than in the two other groups (no carers and non-cohabitant carer). Within the group Func. Cogn. , the cost savings were even greater in situations with a cohabitant carer. Furthermore, the total cost of formal support was significantly lower than in situations with a non-cohabitant carer, despite the high level of disability of the care recipients. All persons in the two disability groups with significant functional limitations (with or without cognitive impairment) were eligible for social care (domestic help, home care worker) and nursing care services. First quartiles and median costs of formal support in these two groups suggested a low level of utilisation of formal support: in the group with 
the highest level of disability, Func. Cogn. (e.g. average total cost for the NIHDI below $€ 57$ per month for 25 per cent of persons with a cohabitant carer). One of the possible explanations for low levels of formal care service use is the difficulty in accessing information on these existing services in Belgium (Anthierens et al., 2014; Cès, Flusin, et al., 2017; Willemse et al., 2016), which may be exacerbated in situations with no carer or with an aged carer.

\section{Strengths and limitations}

We acknowledge the various limitations on our study. First, the estimate of the direct cost of disability was based on an empirical approach (expenditure-based versus living standard approach) (Berthoud, 1991) and does not allow for normatively determining the average costs according to the need of support. The cost observed by using the expenditure-based approach depends on many other factors, such as income constraints of disabled older persons, geographic availability, access to information, etc. Moreover, for cost estimates, some components were excluded as no data was collected, such as the cost to adapt the house for mobility or safety reasons, supplements paid for healthcare services linked to disability, the cost of transportation of informal carers to get to the care recipient's dwelling, the cost of support provided by other informal carers (particularly in situations with a non-cohabitant carer), and the possible overuse of other resources (e.g. heating, transportation facilities, etc.). Lastly, the cost of coordinating formal support was not included.

A second limitation is that the use of the replacement method to value informal care requires a valid and accurate time measurement. For cohabitant carers, time spent on helping activities is less clearly delimited than for non-cohabitant carers, which is mostly determined by physical presence at the care recipient's dwelling. Furthermore, some activities are not easily identifiable, such as supervision, which is likely to be mixed with "being-on-call" (not to include in the time measurement (Cès, De Almeida Mello, et al., 2017). Moreover, the need for supervision is determined subjectively by informal carers and may not correspond to the same appreciation by professionals. For high value of the time spent on caring, overestimation is probable for cohabitant carers and when care recipients have a low or medium level of disability, even after data cleaning. The replacement method also relies 
on a strong hypothesis: formal care is equivalent to informal care (in efficiency and quality) and from the point of view of both the informal carer and care recipients (Koopmanschap et al., 2008; van den Berg et al., 2006; van den Berg, Brouwer and Koopmanschap, 2004). Thirdly, cost unit should correspond to the one of the professional who would replace informal carers. We lacked detailed data on time spent for personal care, which would allow a more accurate cost unit estimation by using a higher hourly rate of a trained home care worker or a nurse (between $€ 22.04$ and $€ 30$ for nursing care). Moreover, in cases of high levels of disability (e.g. significant cognitive impairment), professionals who would replace informal carers should also be trained to look after highly disabled care recipients and would thus, be more costly than a home care worker financed in the setting of a voucher system (van den Berg et al., 2006). The cost of informal support is likely to be underestimated since only the time spent on caring by the main informal carer was included in the estimation.

Fourth, another limitation is regarding selection bias. A significant proportion of disabled older persons may not be included, as they may not apply for formal help for many reasons such as lack of knowledge of existing formal support and lack of awareness of needs, refusal of formal support, financial constrains (Anthierens et al., 2014; Casado, van Vulpen and Davis, 2011; Willemse et al., 2016). The proportion of the situations with no carer or with a cohabitant carer is thus likely to be underestimated, as those involved are less likely to seek formal help than those with non-cohabitant carers. The range of socioeconomic statuses observed in our sample may also not fully represent the entire population of disabled elderly persons as municipalities of low fiscal income households may be underrepresented in our sample.

However, this study is unique for several reasons. On the methodology, we provide a clear delineation of the formal care services included in the cost estimates as there is a need for standardization of the costing estimation, as mentioned with the cost of illness for dementia (Jönsson and Wimo, 2009; Quentin et al., 2010). The methodology to assess time spent on informal care was both carefully and explicitly delimited (Cès, de Almeida Mello, et al., 2017) (e.g. the exclusion of 'normal' tasks) as recommended (van den Berg et al., 2006; Wimo et al., 2016). Data were adjusted according to an explicit justification (limit of 17 hours per day) on the issue of overestimation of time 
spent for informal care as noted by Jönsson (Jönsson and Wimo, 2009). Finally, the large sample size allowed for an accurate calculation of cost estimates per disability profile and presence level of the informal carer in order to benchmark costs. This method overcomes the difficulty to normatively define the amount of resources required since the concept of need is highly relative to the context and perspective (Harrison et al., 2013; Wilkinson-Meyers et al., 2010).

\section{Conclusion}

Our results highlight that informal care costs are the main component of total cost of home support for community-dwelling, disabled older persons. With the aging population, promoting communitybased support may increase the already high costs borne by families. Moreover, there might currently be an underuse of formal support likely to result in critical situations. Indeed, in the two groups with high levels of disability, a significant proportion of persons had relatively low levels of formal support costs (e.g. in the group with high level of disability with no carer). With the rapid demographic change, such issues might be reinforced with the risk of shortage of long-term care services. Hence, to prevent the worsening of situations of disabled older persons and their informal carers, a better detection of seriously disabled older persons living at home with low level of formal support is crucial.

\section{Statement of ethical approval}

The study was approved by the Ethics Committees of each university in the consortium (B40320108337) and the Belgian privacy commission (No. 10/028 modified by CSSSS/16/024).

\section{Statement of funding}

This research project was funded by the National Institute for Health and Disability Insurance (NIHDI), the federal organization that manages and supervises the application of the health compulsory insurance in Belgium.

\section{Declaration of contribution of authors}

All authors contributed substantially to the work. The co-authors have agreed to any changes made.

\section{Conflict of Interest}

No conflict of interest. 


\section{References}

Annemans L (2008) Health economics for non-economists: an introduction to the concepts, methods and pitfalls of health economic evaluations. Gent: Academia Press.

Anthierens S, Willemse E, Remmen R, Schmitz O, Macq J, Declercq A, Arnaut C, Forest M, Denis A, Vinck I, Defourny N and Farfan-Portet M (2014) Support for informal caregivers - an exploratory analysis (D/2014/10.273/40). Belgian Health Care Knowledge Centre (KCE)

Antón J-I, Braña F-J and de Bustillo RM (2016) An analysis of the cost of disability across Europe using the standard of living approach. SERIEs 7, 281-306

Balia S and Brau R (2014) A Country for Old Men? Long-Term Home Care Utilization in Europe. Health Economics 23, 1185-1212

Berthoud R (1991). Meeting the costs of disability. Disability and Social Policy. In (pp. 64100). London: Policy Studies Institute.

Bolin K, Lindgren B and Lundborg P (2008) Informal and formal care among single-living elderly in Europe. Health Economics 17, 393-409

Bonsang E (2009) Does informal care from children to their elderly parents substitute for formal care in Europe? Journal of Health Economics 28, 143-154

Canty A. (2017). Package 'boot' Version 1.3-20. Retrieved from https://cran.rproject.org/web/packages/boot/boot.pdf

Casado BL, van Vulpen KS and Davis SL (2011) Unmet needs for home and community-based services among frail older Americans and their caregivers. Journal of Aging and Health 23, 529-553

Cès S, De Almeida Mello J, Macq J, Van Durme T, Declercq A and Schmitz O (2017) A systematic review of questionnaires used to measure the time spent on family care for frail older people. International Journal of Care and Caring 1, 227-245

Cès S, Flusin D, Schmitz O, Lambert A-S, Pauwen N and Macq J (2017) Les aidants proches des personnes âgées qui vivent à domicile en Belgique : un rôle essentiel et complexe. Fondation Roi Baudouin

Chari AV, Engberg J, Ray KN and Mehrotra AJHsr (2015) The opportunity costs of informal elder-care in the United States: new estimates from the American time use survey. 50, 871-882

De Almeida Mello J, Declercq A, Cès S, Van Durme T, Van Audenhove C and Macq J (2016) Exploring home care interventions for frail older people in Belgium: a comparative effectiveness study. Journal of the American Geriatrics Society 64, 2251-2256

De Almeida Mello J, Van Durme T, Macq J and Declercq A (2012) Interventions to delay institutionalization of frail older persons: design of a longitudinal study in the home care setting. BMC Public Health 12, 615

De Koker B (2009) Socio-demographic determinants of informal caregiving: co-resident versus extra-resident care. European journal of ageing 6, 3-15

Defeyt P (2017) Vers un même régime de pensions pour tous ? Institut pour un Développement Durable 
Degavre F, Nyssens M, Bode I, Breda J, Fernandez J-L and Simonazzi A (2012) Comparing home care for dependent older people in Belgium, England, Germany and Italy.

DiCiccio TJ and Efron B (1996) Bootstrap confidence intervals. Statistical science, 189-212

Drennan VM, Cole L and Iliffe S (2011) A taboo within a stigma? A qualitative study of managing incontinence with people with dementia living at home. BMC Geriatrics 11, 75

Elliott R and Payne K (2005) Essentials of economic evaluation in healthcare. London: Pharmaceutical Press.

ENEO (2017) Pensions et qualité de vie : résultats de l'étude d'Énéo de 2017 Mouvement social des ainés

Eurostat.

Retrieved

from

https://ec.europa.eu/eurostat/tgm/table.do?tab=table\&init=1\&plugin=1\&pcode=tp s00155\&language $=e n$

Evans BC, Coon DW and Crogan NL (2007) Personalismo and breaking barriers: accessing Hispanic populations for clinical services and research. Geriatric nursing 28, 289-296

Fox P, Maslow K and Zhang X (1999) Long-Term Care Eligibility Criteria for People with Alzheimer's Disease. Health Care Financing Review 20, 67-85

Frick KD (2009) Microcosting quantity data collection methods. Medical Care 47, S76-81

Fried LP, Ferrucci L, Darer J, Williamson JD and Anderson G (2004) Untangling the concepts of disability, frailty, and comorbidity: implications for improved targeting and care. Journals of Gerontology. Series A: Biological Sciences and Medical Sciences 59, M255M263

Gerves C, Chauvin P and Bellanger MM (2014) Evaluation of full costs of care for patients with Alzheimer's disease in France: The predominant role of informal care. Health Policy 116, 114-122

Gustavsson A, Cattelin F and Jonsson L (2011) Costs of care in a mild-to-moderate Alzheimer clinical trial sample: Key resources and their determinants. Alzheimer's and Dementia 7, 466-473

Gustavsson A, Jonsson L, Rapp T, Reynish E, Ousset PJ, Andrieu S, Cantet C, Winblad B, Vellas $B$ and Wimo A (2010) Differences in resource use and costs of dementia care between European countries: baseline data from the ICTUS study. Journal of Nutrition Health and Aging 14, 648-654

Harrison JD, Young JM, Butow PN and Solomon MJ (2013) Needs in health care: what beast is that? International Journal of Health Services 43, 567-585

Hartmaier SL, Sloane PD, Guess HA, Koch GG, Mitchell CM and Phillips CD (1995) Validation of the minimum data set cognitive performance scale: agreement with the minimental state examination. Journals of Gerontology. Series A: Biological Sciences and Medical Sciences 50, M128-M133

Hastie TJ, Tibshirani RJ and Friedman JH (2009) The elements of statistical learning: data mining, inference, and prediction: Springer.

Hirsch D and Hill K (2016) The additional cost of disability: a new measure and its application to sensory impairment. Disability \& Society $31,897-913$ 
Jonsson $L$, Jonhagen ME, Kilander $L$, Soininen $H$, Hallikainen $M$, Waldemar $G$, Nygaard $H$, Andreasen N, Winblad B and Wimo A (2006) Determinants of costs of care for patients with Alzheimer's disease. International Journal of Geriatric Psychiatry 21, 449-459

Jönsson L and Wimo A (2009) The cost of dementia in Europe. PharmacoEconomics 27, 391403

Katz S, Ford AB, Moskowitz RW, Jackson BA and Jaffe MW (1963) Studies of Illness in the Aged The Index of ADL: A Standardized Measure of biological and Psychosocial Function. Journal of the American Medical Association 185, 914-919

Koopmanschap MA, van Exel NJA, van den Berg B and Brouwer WB (2008) An overview of methods and applications to value informal care in economic evaluations of healthcare. PharmacoEconomics 26, 269-280

Lavoie JP (2000) Familles et soutien aux parents âgées dépendants. Montréal: L'Harmattan.

Le S, Josse J and Husson F (2008) FactoMineR: An R Package for Multivariate Analysis. Journal of Statistical Software 25, 1-18

Litwin $\mathrm{H}$ and Attias-Donfut C (2009) The inter-relationship between formal and informal care: a study in France and Israel. Ageing \& Society 29, 71-91

Mihaylova B, Briggs A, O'Hagan A and Thompson SG (2011) Review of statistical methods for analysing healthcare resources and costs. Health Economics 20, 897-916

Morciano M, Hancock R and Pudney S (2015) Disability costs and equivalence scales in the older population in Great Britain. Review of Income and Wealth 61, 494-514

Morris JN, Fries BE, Mehr DR, Hawes C, Phillips C, Mor V and Lipsitz LA (1994) MDS cognitive performance scale $@$. Journal of Gerontology 49, M174-M182

Morris JN, Fries BE and Morris SA (1999) Scaling ADLs within the MDS. Journals of Gerontology. Series A: Biological Sciences and Medical Sciences 54, M546-M553

OECD (2016). Ressources et utilisation des soins de longue durée https://www.oecdilibrary.org/content/data/data-00543-fr

OECD (2017) Health at a Glance 2017 : OECD Indicators. OECD Publishing

Paraponaris A, Davin B and Verger P (2012) Formal and informal care for disabled elderly living in the community: an appraisal of French care composition and costs. The European Journal of Health Economics 13, 327-336

Posnett J and Jan S (1996) Indirect cost in economic evaluation: the opportunity cost of unpaid inputs. Health Economics 5, 13-23

Quentin W, Riedel-Heller S, Luppa M, Rudolph A and König HH (2010) Cost-of-illness studies of dementia: a systematic review focusing on stage dependency of costs. Acta Psychiatrica Scandinavica 121, 243-259

Rolfson DB, Majumdar SR, Tsuyuki RT, Tahir A and Rockwood K (2006) Validity and reliability of the Edmonton Frail Scale. Age and Ageing 35, 526-529

Salvador-Carulla L and Gasca VI (2010) Defining disability, functioning, autonomy and dependency in person-centered medicine and integrated care. International Journal of Integrated Care 10 
Schooreel T and Valsamis D (2017). Evaluation du système des titres-services pour les emplois et services de proximité en Région de Bruxelles-Capitale, 2016. In. Bruxelles: Service public régional de Bruxelles, Economie et Emploi, Service Emploi.

Schwarzkopf L, Menn P, Kunz S, Holle R, Lauterberg J, Marx P, Mehlig H, Wunder S, Leidl R, Donath $C$ and Graessel E (2011) Costs of care for dementia patients in community setting: an analysis for mild and moderate disease stage. Value Health 14, 827-835

Spillman BC and Lubitz J (2000) The effect of longevity on spending for acute and long-term care. New England Journal of Medicine 342, 1409-1415

Statbel. (2017). An overview of Belgian wages and salaries Belgium in figures. Retrieved from https://statbel.fgov.be/en/news/overview-belgian-wages-and-salaries

Suh G-H, Knapp M and Kang C-J (2006) The economic costs of dementia in Korea, 2002. International Journal of Geriatric Psychiatry 21, 722-728

Tan SS, Rutten FFH, van Ineveld BM, Redekop WK and Hakkaart-van Roijen L (2009) Comparing methodologies for the cost estimation of hospital services. The European Journal of Health Economics 10, 39-45

Taylor Jr DH, Schenkman M, Zhou J and Sloan FA (2001) The relative effect of Alzheimer's disease and related dementias, disability, and comorbidities on cost of care for elderly persons. Journals of Gerontology. Series A: Biological Sciences and Medical Sciences 56, S285-S293

van den Berg B, Brouwer W, van Exel J and Koopmanschap M (2005) Economic valuation of informal care: the contingent valuation method applied to informal caregiving. Health Economics 14, 169-183

van den Berg B, Brouwer W, van Exel J, Koopmanschap M, van den Bos GAM and Rutten $F$ (2006) Economic valuation of informal care: lessons from the application of the opportunity costs and proxy good methods. Social Science \& Medicine (1982) 62, 835845

van den Berg B, Brouwer WBF and Koopmanschap MA (2004) Economic Valuation of Informal Care: An Overview of Methods and Applications. The European Journal of Health Economics 5, 36-45

Van den Bosch K, Willemé P, Geerts J, Breda J, Peeters S, Van De Sande S, Vrijens F, Van de Voorde C and Stordeur S (2011) Soins résidentiels pour les personnes âgées en Belgique : projections 2011 - 2025 (D/2011/10.273/64). Belgian Health Care Knowledge Centre (KCE)

Van der Heyden J and Charafeddine R (2014). Enquête de santé 2013. Rapport 1 : Santé et Bien-être. Résumé des principaux résultats. In (Vol. D/2014/2505/53): Institut Scientifique de Santé Publique, Bruxelles.

Vrijens F, Renard F, Camberlin C, Desomer A, Dubois C, Jonckheer P, Van den Heede K, Van de Voorde $C$, Warkiers D, Léonard C and Meeus $P$ (2016). Performance of the Belgian Health System - Report 2015. In KCE Report (Vol. KCE report 259S). Brussels: Belgian Health Care Knowledge Centre (KCE).

Wilkinson-Meyers L, Brown P, McNeill R, Patston P, Dylan S and Baker R (2010) Estimating the additional cost of disability: Beyond budget standards. Social Science \& Medicine (1982) 71, 1882-1889 
Willemé P, Geerts J, Cantillon B and Mussche N (2011) Long-Term Care Financing in Belgium. In J. Costa-Font \& C. Courbage (Eds.), Financing Long-Term Care in Europe.

Willemse E, Anthierens S, Farfan-Portet MI, Schmitz O, Macq J, Bastiaens H, Dilles T and Remmen R (2016) Do informal caregivers for elderly in the community use support measures? A qualitative study in five European countries. BMC Health Services Research 16, 270

Wimo A, Jönsson L, Fratiglioni L, Sandman PO, Gustavsson A, Sköldunger A and Johansson L (2016) The societal costs of dementia in Sweden 2012-relevance and methodological challenges in valuing informal care. Alzheimer's Research \& Therapy 8, 59

Wimo A, Jönsson L, Gustavsson A, McDaid D, Ersek K, Georges J, Gulacsi L, Karpati K, Kenigsberg $\mathrm{P}$ and Valtonen $\mathrm{H}$ (2011) The economic impact of dementia in Europe in 2008-cost estimates from the Eurocode project. International Journal of Geriatric Psychiatry 26, 825-832

Wubker A, Zwakhalen SMG, Challis D, Suhonen R, Karlsson S, Zabalegui A, Soto M, Saks K and Sauerland D (2014) Costs of care for people with dementia just before and after nursing home placement: primary data from eight European countries. The European Journal of Health Economics 16, 689-707 